\title{
INVESTIGATION OF VALUE INNOVATION POTENTIAL UNDER TRANSITIONAL CONDITIONS IN SERBIA
}

\author{
Dragana Živković, Dragan Manasijević, Nada Štrbac, Milica Niculović, Jelena Živadinović \\ University of Belgrade, Technical Faculty in Bor, Serbia \\ Corresponding author: \\ Dragana Živković \\ University of Belgrade \\ Technical Faculty in Bor \\ VJ 12, 19210 Bor, Serbia \\ phone: +38130424555 \\ e-mail:dzivkovic@tf.bor.ac.rs
}

Received: 22 April 2015 Accepted: 6 May 2015

\begin{abstract}
Nowadays, business environment is faster than ever in the field of new technologies. The firms are forced to find new ways to compete and survive through innovations. To meet these demands, different tools and techniques are used in order to measure capability of firms to innovate. One of them is the Value Innovation Potential Assessment Tool, which helps to identify appropriate opportunities for firms to use it to assess their effectiveness of innovation work. The main goal of this paper was to investigate the Value Innovation Potential under transitional conditions in some firms in South-Eastern Serbia. The research was done using a questionnaire taken from literature, which was applied to one hundred employees in mentioned Serbian firms. The data were statistically analysed, explained and main conclusions were obtained. Proposed factor model of Value Innovation Potential was tested using confirmatory factor analysis (CFA) on investigated population.
\end{abstract}

KEYWORDS

innovation, value innovation potential, transition.

\section{Introduction}

In actual competitive race for success, there is a need for each organization to develop their own technology. This constant uncertainty brought new rules in doing business. No longer is one person a top strategist or an expert in the organization. On the contrary, all employees must learn to use maximum of their potentials at all levels of organization. The learning organization is an organization where people are constantly developing their skills of creating and achieving results they truly desire, where new models and patterns are fostered, where collective aspirations are free to express and where continuous learning is all about how to learn together. These organizations learn and create knowledge faster, applying it in practice, becoming more successful than competitors. It is believed that learning and knowledge are the most important sources of competitive advantage, and that learning organizations are more successful than others. Their main characteristics are: organization in order to acquire knowledge, introduction of rapid change and innovation, effective team work and leadership [1].

The learning organization has an organizational culture that promotes and supports innovation and learning - individually, in groups and collectively [2]. Therefore, an innovative culture is considered to be one of the key factors of innovative companies [3]. Innovation represents a process where creative idea is taken and turned into a beneficial product, service, or method of operation [4] while innovation process involves a series of scientific, technological, organizational, financial and commercial activities. In addition to research and development (R\&D), several activities take place in innovation process such as development tools, industrial engineering, preparation for production and pre-production development, new products marketing, acquisitions of unincorporated technology and design. The core of innovation is a value creation. It enhances value of the product, its essential attributes or combinations of at- 
tributes, through knowledge infrastructure and physical infrastructure. Innovation as a creator of value moves economy from the vicious circle of difficulties of the economic system such as deterioration of firms. This could be overcome by strengthening innovation strategy, entrepreneurship and creativity in the organization. In this way, the number and quality of ideas (inventions) of new technology products and processes is increased [5].

\section{Managing Innovation Potential under transitional conditions}

The topic of technological and economic competition is very popular among researchers from transition countries. Starting from Verspagen's point of view, there are two factors that can prevent competition through technological diffusion: technological congruence and social capability. Technological congruence is defined as a struggle between technologies used in developed countries and technologies most suitable for induction in less developed countries. This means that some technologies used in developed countries are not suitable for countries in transition due to many factors. On the other hand, social capability is defined in concept of institutional factors such as educational system, banking system, political system, etc. It creates key differences in social skills through innovations - both hard technological and soft organizational innovations [6].

Fagerberg and Srholec point out that openness to trading and foreign direct investment (FDI) may not be crucial for development. It was concluded that poor countries are less capable to take advantage of foreign direct investment due to lower level of absorption capacity [7]. Empirical analysis shows that countries who are interested in being progressive and competitive had well-developed innovation system. This means that there is a strong and significant statistical relationship between GDP per capita at one side, and innovation system on the other side [8]. According to Dyker and Radosevic, there are two possible scenarios for countries in transition. All countries do not have the same starting position which will influence on their future economic growth. The most acceptable scenario for whole region in transition over the next few decades is that a group of CEE countries is at the level of economic development, which is quite high, but still below the EU average. On the contrary, countries of the former Soviet Union and some Balkan countries continue to lag behind, as they did in the past decade, or, in the best case scenario, these countries could establish the trajectory of technological competition in future period [8]. In transition economies, the emphasis is placed on creating political and economic environment in which organization will develop. Less attention is given to the people in organization [9].

\section{Transitional conditions in Serbia}

Serbia has several strategic competitive advantages, including knowledge of regional and international markets and access to these markets, excellent conditions for agriculture and tourism potential, strategic position on the main European continental road as well as on one of the leading waterway. Despite the fact that among main objectives of policy of the Government of Serbia are fundamental economic reforms and industry restructuring, country is still facing with major constraints on economic development. Enterprise restructuring has been delayed, foreign direct investment are drastically lower than reported in the previous years, there is a huge trade deficit, unemployment remains high, there is a mismatch between supply and demand in the labor market and labor costs are very high. Investments essential to economic prosperity of Serbia from short to long term, such as investments in new equipment, technology and human resources, does not currently exist in significant proportions.

Individual companies of all sizes, in manufacturing or service sectors, are faced with enormous obstacles, both within Serbian or potential export markets. Problems may include: lack of capital and technology, lack of marketing understanding and management expertise, low level of product development and innovation, poor packing and packaging, lack of product certification systems, incomplete legal framework, expensive floating capital, lack of financial instruments involved in exports, lack of infrastructure and low level of knowledge of Western European languages in many companies.

Trade agreements with the European Union and Russia, together with the creation of a free trade zone in Southeastern Europe, offer important opportunities. According to the World Bank Group "Serbia's main exports are cars and other products from the automotive sector. Automotive exports have become the most important sector following significant investments from Italian carmaker FIAT. Almost 90\% of all Serbian exports go to Europe - 55\% to the EU and about $33 \%$ to the Central European Free Trade Agreement (CEFTA) region. Exports of services are also gaining in importance, reaching $10 \%$ of GDP in 2013" [10].

Although business environment is better than several years ago, it is crucial for Serbian companies 
to improve their innovations in order to achieve competitiveness. Development of management capacity, introduction of quality control system in the company's operations, encouraging innovation and latest technology application are predicted. Serbian budget for research and development (approximately 100 million euros) is allocated to all scientific disciplines, and there is no area of basic research that annually receives more than 10 million euros. The biggest funds are for chemistry (7.7 million), social sciences (7.1 million), biology (6.9 million) and physics (5.4 million). In the field of technological development, each area receives five million per year except bioengineering and agro-industry (14.2 million). Serbia is threatened by a new wave of "brain drain" unless investment in science and development is increased, which is currently only $0.3 \%$ of GDP per year while the average EU annual investment in research and development is around 2\% of GDP per year [11].

Having all these facts in mind it is important to work on improvement of innovation potential in Serbian organizations, in order to be ready for the strong competitive race at the global market. According to previous research [12], the Value Innovation Potential Assessment Tool - or so called Value IQ tool is widely used to identify appropriate opportunities for organizations to assess their Value Innovation potential [12]. Value IQ tool consists of nine dimensions - Meaningful Work, Risk-taking Culture, Customer Orientation, Agile Decision-Making, Open Communication, Business Planning, Learning Organization, Business Intelligence, Empowerment. Therefore, the objective of this study was to investigate current value of innovation potential using Value IQ tool questionnaire and to check validity of mentioned factors structure under transitional conditions nowadays in Serbia.

\section{Research methods}

Bearing in mind that Serbia is still under transitional conditions, it is important to investigate how Serbian employees are innovative, since innovation is crucial to innovative potential of each organization. The research was conducted in several organizations in the municipalities of Bor, Niš and Aleksinac (South-Eastern Serbia). Survey target group consisted of 100 employees from different organizations, including state and private firms and public institutions in mentioned municipalities. The respondents were taken randomly among managers, workers, top management, RD sector, marketing, etc.
A questionnaire, concerning investigated Value IQ tool, was taken from [13] and it was used as a research tool for collecting data.

Table 1

Value IQ tool Questionnaire [13].

Meaningful Work (MW)

1. People know that what they do impacts what happens in the organization

2. The work we do in the organization is meaningful

Risk-Taking Culture (RTC)

3. Being innovative is characteristic of the organization's culture

4. The organization's culture encourages employees to try new ideas

5. Being willing to take risks is characteristic of the organization

6. The organization is adaptable to new situations Customer Orientation (CO)

7. In the organization, we regularly look at how we offer customers superior value

8. In the organization, we regularly re-examine who are the target customers for what we do

9. We are encouraged to think in terms of total customer solutions

Agile Decision-Making (ADM)

10. In the organization, we assess business opportunities without being constrained by where we are right now

11. In the organization, decisions are usually made at the level where the best information is available

12. Everyone is involved to some degree in our business planning

Business Intelligence (BI)

13. In the organization, we regularly monitor competitors

14. In the organization, we use competitors as our benchmark

Open Communication (OC)

15. Employees feel free to challenge the status quo

16. People feel it's OK to speak out if they disagree with others' decisions

Empowerment (E)

17. People are encouraged to identify concerns about work 18. Individual independence is respected by the organization

Business Planning (BP)

19. In the organization, we use scenario planning as part of our business plan creation

20. In the organization, we use simulations as part of our business plan creation

21. The organization takes a broad value chain perspective when examining new opportunities

Learning Organization (LO)

22 . When redesigning products (or services) we maximize what employees have learned from their working experiences

23. One of our innovation practices is finding out how our customers really use our products 
The total 100 correctly filled questionnaires were collected from the respondents. During data collecting stage of the research, the anonymity and confidentiality of data was ensured. In order to evaluate the statements within applied questionnaire, Likert five-point scale was used (I-Absolutely not agree; II-Not agree; III-Neutral; IV-Agree; V-Absolutely agree). Respondents were asked to indicate their level of agreement with statements from Value IQ tool Questionnaire.

Some additional questions concerning demographic profile of the respondents were also used. So, among total number of investigated respondents, $68 \%$ were male and $32 \%$ were female. Most of the participants were between 18 and 30 years old (62\%), followed by respondents whose age ranged from 30 to 50 years $(34 \%)$ and respondents who were over 50
(4\%). Considering their education, $3 \%$ of the respondents have primary education, $27 \%$ have secondary education, $14 \%$ were with higher education, while $56 \%$ of the respondents were with the faculty degree.

Collected data were processed in SPSS 18.0 software, while confirmatory factor analysis (CFA) was done using LISREL 8.80 software.

\section{Results and discussion}

\section{Descriptive statistics}

The results of descriptive statistics analysis obtained for Value IQ tool by collecting data using a questionnaire (Table 1) among the respondents in the organizations in the municipalities Bor, Niš and Aleksinac (Serbia) are presented in Table 2.

Table 2

Frequencies of the answers according to the Value IQ tool questionnaire items:

I - absolutely not agree; II - not agree; III - neutral; IV - agree; V - absolutely agree.

\begin{tabular}{|c|c|c|c|c|c|c|}
\hline No & Item & I & II & III & IV & $\mathrm{V}$ \\
\hline 1 & People know that what they do impacts what happens in the organization (MW) & 6 & 14 & 16 & 28 & 36 \\
\hline 2 & The work we do in the organization is meaningful (MW) & 10 & 18 & 16 & 26 & 30 \\
\hline 3 & Being innovative is characteristic of the organization's culture (RTC) & 14 & 16 & 0 & 50 & 20 \\
\hline 4 & The organization's culture encourages employees to try new ideas (RTC) & 12 & 14 & 8 & 38 & 28 \\
\hline 5 & Being willing to take risks is characteristic of the organization (RTC) & 22 & 18 & 14 & 30 & 16 \\
\hline 6 & The organization is adaptable to new situations (RTC) & 16 & 8 & 0 & 24 & 52 \\
\hline 7 & In the organization, we regularly look at how we offer customers superior value (CO) & 8 & 20 & 46 & 22 & 4 \\
\hline 8 & $\begin{array}{l}\text { In the organization, we regularly re-examine who are the target customers for what } \\
\text { we do }(\mathrm{CO})\end{array}$ & 4 & 10 & 6 & 54 & 26 \\
\hline 9 & We are encouraged to think in terms of total customer solutions (CO) & 10 & 20 & 22 & 30 & 18 \\
\hline 10 & $\begin{array}{l}\text { In the organization, we assess business opportunities without being constrained by } \\
\text { where we are right now (ADM) }\end{array}$ & 6 & 10 & 34 & 38 & 12 \\
\hline 11 & $\begin{array}{l}\text { In the organization, decisions are usually made at the level where the best information } \\
\text { is available (ADM) }\end{array}$ & 4 & 10 & 8 & 42 & 36 \\
\hline 12 & Everyone is involved to some degree in our business planning (ADM) & 12 & 42 & 14 & 26 & 6 \\
\hline 13 & In the organization, we regularly monitor competitors (BI) & 4 & 10 & 18 & 50 & 18 \\
\hline 14 & In the organization, we use competitors as our benchmark (BI) & 0 & 12 & 26 & 30 & 32 \\
\hline 15 & Employees feel free to challenge the status quo (OC) & 6 & 26 & 28 & 32 & 8 \\
\hline 16 & People feel it's OK to speak out if they disagree with others' decisions (OC) & 14 & 20 & 18 & 28 & 20 \\
\hline 17 & People are encouraged to identify concerns about work (E) & 6 & 16 & 22 & 38 & 18 \\
\hline 18 & Individual independence is respected by the organization $(\mathrm{E})$ & 0 & 18 & 50 & 30 & 2 \\
\hline 19 & $\begin{array}{l}\text { In the organization, we use scenario planning as part of our business plan creation } \\
\text { (BP) }\end{array}$ & 8 & 8 & 8 & 24 & 52 \\
\hline 20 & In the organization, we use simulations as part of our business plan creation (BP) & 4 & 12 & 32 & 18 & 34 \\
\hline 21 & $\begin{array}{l}\text { The organization takes a broad value chain perspective when examining new oppor- } \\
\text { tunities (BP) }\end{array}$ & 4 & 10 & 20 & 30 & 36 \\
\hline 22 & $\begin{array}{l}\text { When redesigning products (or services) we maximize what employees have learned } \\
\text { from their working experiences (LO) }\end{array}$ & 0 & 8 & 16 & 32 & 44 \\
\hline 23 & $\begin{array}{l}\text { One of our innovation practices is finding out how our customers really use our } \\
\text { products (LO) }\end{array}$ & 6 & 8 & 10 & 34 & 42 \\
\hline
\end{tabular}


The respondents showed the highest level of agreement with the statements under number 19 (52\%), $22(44 \%)$ and 23 (42\%); they agreed with statements under number 3 (50\%), 8 (54\%), 11 $(42 \%)$ and $13(50 \%)$. The lowest level of agreement was identified for the statement under number 12 $(42 \%)$. The questions most respondents showed neutral opinion were 7 (46\%) and 18 (50\%).

According to obtained results, more than a half of respondents confirmed that in their organizations, they regularly re-examine who are the target customers for what they do (54\%), use scenario planning as part of their business plan creation (52\%), regularly monitor competitors (50\%) and their innovativeness is characteristic of the organization's culture $(50 \%)$. It is also interesting that majority of respondents consider themselves not involved in business planning in some degree, while $50 \%$ of respondents feels that their individual independence is not respected by the organization.

\section{Model testing}

Confirmatory factor analysis [14] was used to test proposed factor model of the Value IQ tool [13] on present population of Serbian employees, according to which Value Innovation Potential includes nine investigated dimensions: Meaningful Work (MW), Risk-taking Culture (RTC), Customer Orientation (CO), Agile Decision-Making (ADM), Open Communication (OC), Business Planning (BP), Learning Organization (LO), Business Intelligence (BI) and Empowerment (E), given in detail in Table 1. These dimensions were incorporated in the conceptual model examined in this work, as shown in Fig. 1.

The examined model shows hypothesized relationships between observed variables (indicators statements from the Value IQ tool questionnaire used for data collection) and latent variables (factors - dimensions of the Value IQ tool).

Having in mind proposed objectives of the research, following hypotheses were incorporated in conceptual model and tested with our obtained data:

- Hypothesis (H1): It is possible to identify the dimensions of the conceptual model of innovation potential in the transition conditions;

- Hypothesis (H2): It is possible to measure, monitor and compare dimensions that characterize the conceptual model of innovation potential in the transition conditions;

- Hypothesis (H3): There is a strong interdependence of dimensions that affect the values of the conceptual model innovation potential.

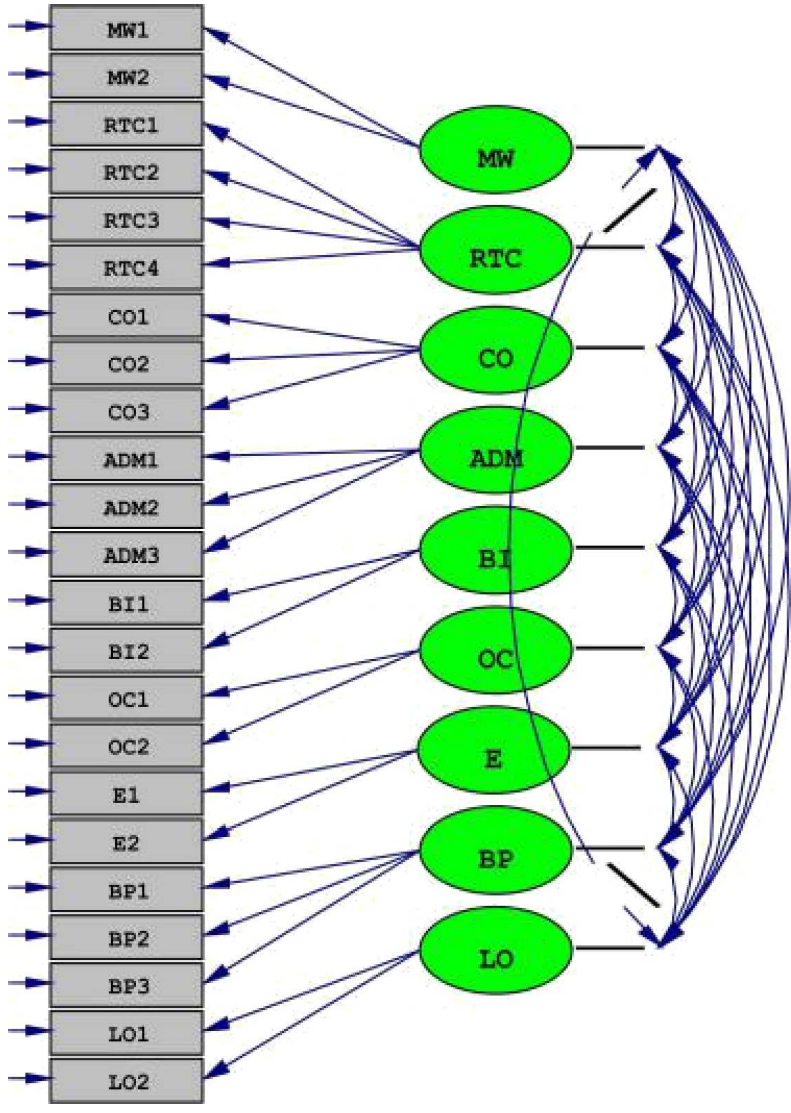

Fig. 1. Examined conceptual model.

Accepting the model of 23 variables divided into nine dimensions - Meaningful Work (2 items), Risk-taking Culture (4 items), Customer Orientation (3 items), Agile Decision-Making (3 items), Business Intelligence (2 items), Open Communication (2 items), Empowerment (2 items), Business Planning (3 items) and Learning Organization (2 items) is based on an estimated parameters of the CFA.

Numerous goodness-of-fit measures are available to assess the overall fit of the given model. They measure the extent to which the actual or observed covariance input matrix corresponds with (or departs from) that predicted from the proposed model [15].

Chi-square (X2) presents a basic measure of that kind, showing how the model fits the data comparing the sample variance covariance matrix with the implied variance covariance matrix. Relative X2/df ratio should be less than 5 .

Tucker-Lewis Index (TLI) is a goodness of fit measure adjusted for model complexity in relation to a baseline model. Good fitting models have values of Comparative Fit Index (CFI) 0.90 and above [16]. The values close to 1 indicates a good model fit. Also, the Root Mean Square Error of Approximation (RMSEA) should be below 0.1 [17]. 
All mentioned goodness of fit measures for the conceptual model applied in this work are calculated using LISREL 8.80 program and given in Table 3 together with related acceptable values.

Table 3

Fit indices for the conceptual model.

\begin{tabular}{c|c|c}
\hline $\begin{array}{c}\text { Fit } \\
\text { indices }\end{array}$ & $\begin{array}{c}\text { Accepted } \\
\text { fit }\end{array}$ & $\begin{array}{c}\text { Model fit results } \\
\text { (hypothesized model) }\end{array}$ \\
\hline $\mathrm{X}^{2}(\mathrm{CMIN})$ & & 914.42 \\
\hline $\mathrm{df}$ & & 194 \\
\hline $\mathrm{X}^{2} / \mathrm{df}$ & $3<\mathrm{X}^{2} / \mathrm{df}<5$ & 4.714 \\
\hline $\mathrm{CFI}$ & $0.90<\mathrm{CFI}<1.0$ & 0.960 \\
\hline $\mathrm{TLI}$ & $0.85<\mathrm{TLI}<0.95$ & 0.852 \\
\hline $\mathrm{IFI}$ & $0.90<\mathrm{IFI}<0.95$ & 0.960 \\
\hline RMSEA & $0.05<\mathrm{RMSEA}<0.1$ & 0.095
\end{tabular}

In Fig. 2 conceptual model with calculated regression weights between latent variables and indicators are given, as well as the correlations between latent variables.

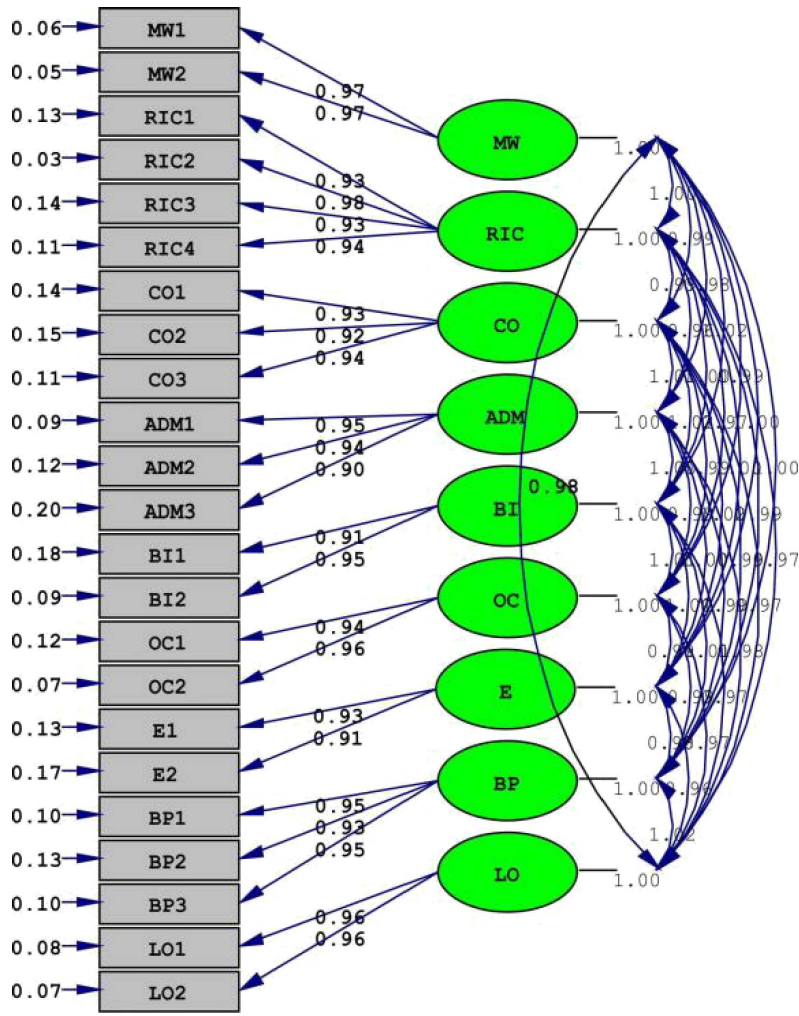

Fig. 2. Conceptual model with calculated regression weights between latent variables and indicators.

All standardized regression weights have high values, close to 1 , which indicates that latent variables are good described with their corresponding indicators. Also, all correlations between latent variables have high positive values, close to 1 , which suggests strong positive association between the dimensions of the Value IQ tool.

Calculated T-values for all statistical indicators (Fig. 2), presented in Fig. 3, confirm significance of statistical parameters given in Fig. 2.

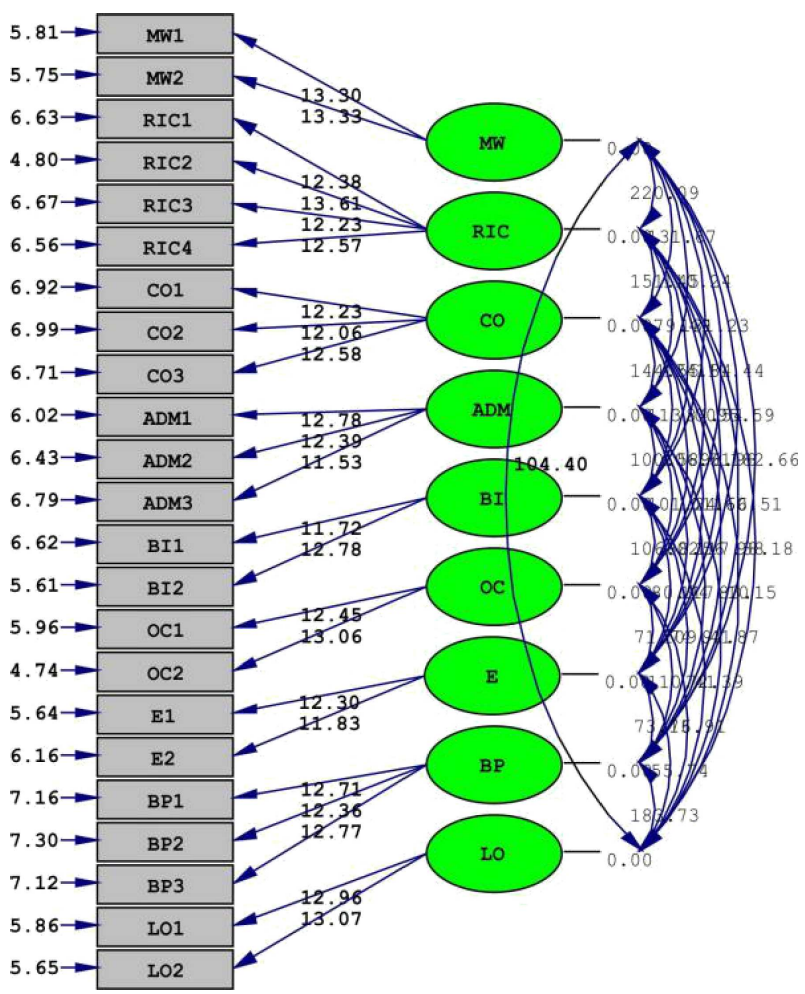

Fig. 3. Calculated T-values for all statistical indicators.

In this way, starting hypothesis are confirmed, and also used conceptual model with nine dimensions of the Value IQ tool is applicable for investigated population in this study. It means that obtained values correspond to reference recommendations. Thus, the model innovation potential (IQ) is accepted as enforceable model for testing the value of innovation potential in the transitional conditions [18].

\section{Conclusion}

The new knowledge-based economy puts new demands on all organizations. They need to transform their operations and to adapt new economy. The knowledge society must have a learning organization with all elements of an organization that teaches and supports innovation. In order to successfully operate and improve the value of innovation potential, organization must be able to measure intangible value of the newly created dimension of innovation potentials that arise as a result of innovation management. 
New findings on value of innovation potential under transitional conditions in Serbia are presented in this work. The results obtained by value IQ tool questionnaire application to several organizations in some Serbian municipalities (Bor, Niš, Aleksinac), showed that it is possible to identify the dimensions of the conceptual model of innovation potential in the transition conditions and that there is a strong interdependence of dimensions that affect the values of the conceptual model innovation potential. Also, according to the respondents' opinion, few dimensions from the Value of Innovation Potential are already highly presented in business practice in Serbia - such as that in their organizations, they regularly re-examine who are the target customers for what they do, use scenario planning as part of their business plan creation, regularly monitor competitors and their innovativeness is characteristic of the organization's culture.

Having in mind the results presented in this study, such methodology can be taken as a good example of practice which can contribute to the examination of the value of intangible innovation potential in organizations under transitional conditions.

The authors are grateful to Dr Ljubiša Balanović for his assistence during the preparation of this work.

\section{References}

[1] Lei D., Slocum J.W., Pitts R.A., Designing organizations for competitive advantage: The power of unlearning and learning, Organizational Dynamics, 27, 3, 24-38, 1999.

[2] Easterby-Smith M., Crossan M., Nicolini D., Organizational learning: debates past, present and future, Journal of Management Studies, 37, 6, 783796, 2000.

[3] Jones R.A., Jimmieson N.L., Griffiths A., The impact of organizational culture and reshaping capabilities on change implementation success: the mediating role of readiness for change, Journal of Management Studies, 42, 2, 361-386, 2005.

[4] Fengjing H., Dongdong H., Empirical Research on the Effects of Organizational Innovation on Organizational Performance based on mediator effect of dynamic core competence of enterprise, JCIT, 7, 6, 185-192, 2012.

[5] Jakšić L.M., Strategical technology management: Innovations, management and entrepreneurship, FON, Belgrade, 2001 (in Serbian).
[6] Verspagen B., A global perspective on technology and economic performance, and the implications for the post-socialist countries, in Dyker D.A. and Radosevic S. [Eds.], Innovation and structural change in Post-socialist Countries: a Quantitative Approach, Dordrecht, Kluwer, 29-44, 1999.

[7] Fagerberg J., Srholec M., National innovation system, capabilities and economic development, Research Policy, 37, 1417-1435, 2008.

[8] Dyker D.A., Radosevic S., Building Social Capability for Economic Catch-up: The Experiences and Prospectus of the Post-socialist Countries, Innovation, 14, 3, 219-237, 2001.

[9] Leskovar-Spacapan G., Bastic M., Differences in organizations innovation capability in transition economy: Internal aspect of organizations strategic orientation, Technovation, 27, 9, 533-546, 2007.

[10] http://www.worldbank.org/en/country/serbia/ overview

[11] http://www.danas.rs/danasrs/ekonomija/nuzna_ veca_ulaganja_u_nauku.4.html?news_id $=281338$

[12] Aiman-Smith L., Goodrich N., Roberts D., Scinta J., Assessing your organization's potential for value innovation, Research Technology Management, Washington, 48, 2, 37-42, 2005.

[13] Chang J.C., Strengthening Value Innovation Potential - A Study of Innovation-Oriented Industry in Taiwan, International Journal of Advancements in Computing Technology (IJACT), 5, 4, 882-889, 2013.

[14] Hurley A.E., Scandura T.A., Schriesheim C.A., Brannick M.T., Seers A., Vandenberg R.J., Williams L.J., Exploratory and confirmatory factor analysis: guidelines, issues, and alternatives, Journal of Organizational Behavior, 18, 667-683, 1997.

[15] Ho R., Handbook of univariate and multivariate data analysis and interpretation with SPSS2006, Rockhampton, AustraliaChapman \& Hall/CRC, Taylor \& Francis Group, 2006.

[16] Isaac R.G., Herremans I.M., Kline T.J., Intellectual Capital Management Enablers: A Structural Equation Modeling Analysis, Journal of Business Ethics, 93, 3, 373-391, 2010.

[17] Browne M.W., Cudek R., Alternative ways of assessing model fit. Sociological Methods 8 Research, 21, 230-258, 1992.

[18] Ahire S.L., Golhar D.Y., Waller M.A., Development and validation of TQM implementation constructs, Decision Sciences, 27, 1, 23-56, 1996. 